\title{
Signatures of moving polar cap arcs in the F-region PolarDARN echoes
}

\author{
A. V. Koustov ${ }^{1,2}$, K. Hosokawa ${ }^{3}$, N. Nishitani ${ }^{1}$, K. Shiokawa ${ }^{1}$, and H. Liu ${ }^{2}$ \\ ${ }^{1}$ Solar-Terrestrial Environment Laboratory, Nagoya University, Furo-Cho, Chikusa-ku, Nagoya 464-8601, Japan \\ ${ }^{2}$ Institute of Space and Atmospheric Studies, University of Saskatchewan, 116 Science Place, Saskatoon, S7N 5E2, Canada \\ ${ }^{3}$ Department of Communication Engineering and Informatics, University of Electro-Communications, Chofugaoka 1-5-1, \\ Chofu, Tokyo 182-8585, Japan
}

Correspondence to: A. V. Koustov (sasha.koustov@usask.ca)

Received: 28 October 2011 - Revised: 23 February 2012 - Accepted: 24 February 2012 - Published: 1 March 2012

\begin{abstract}
Joint observations of the all-sky camera at Resolute Bay (Nunavut, Canada) and the Polar Dual Auroral Radar Network (PolarDARN) HF radars at Rankin Inlet and Inuvik (Canada) are considered to establish radar signatures of poleward moving polar cap arcs "detaching" from the auroral oval. Common features of the events considered are enhanced power or echo occurrence in the wake of the arcs and enhanced spectral width of these echoes. When the arcs were oriented along some of the radar beams, velocity reversals at the arc location were observed with the directions of the arc-associated flows corresponding to a converging electric field. For the event of 9 December 2007, two arcs were poleward progressing almost along the central beams of the Inuvik radar at the speed close to the $\boldsymbol{E} \times \boldsymbol{B}$ drift of the bulk of the F-region plasma as inferred from HF Doppler velocities and from independent measurements by the Resolute Bay ionosonde. In global-scale convection maps inferred from all Super Dual Auroral Radar Network (SuperDARN) radar measurements, the polar cap arcs were often seen close to the reversal line of additional mesoscale convection cells located poleward of the normal cells related to the auroral oval.
\end{abstract}

Keywords. Ionosphere (Electric fields and currents; Ionospheric irregularities) - Magnetospheric physics (Polar cap phenomena)

\section{Introduction}

Over the years, the Super Dual Auroral Radar Network (SuperDARN) HF radars have been very useful in studying various high-latitude phenomena (Chisham et al., 2007). One area of research that has not been thoroughly addressed is plasma flows around bright optical forms. This is in contrast to VHF and UHF coherent radar E-region studies (e.g. Greenwald, 1977; Uspensky et al., 2001). Uspensky et al. (2001) gave an example of the Hankasalmi SuperDARN radar echo detection $\sim 100-200 \mathrm{~km}$ equatorward of an evening arc drifting equatorward. Milan et al. (1999) discussed echoes associated with an arc without presenting actual data on the aurora. The echoes were seen around the arc, both poleward and equatorward of it, as separate bands shifting together with the arc whose location was clearly identified at a point of its crossing the EISCAT radar zenith. Séran et al. (2009) investigated another single event, with limited Hankasalmi radar echo coverage around a weak auroral zone arc. In the above studies, higher echo occurrence around the arcs would have been helpful in making more comprehensive conclusions.

The deficiency of HF echoes in the vicinity of auroral arcs has been puzzling for years. The gradient-drift (GD) instability is believed to be the main source of plasma irregularities causing HF backscatter (e.g. Tsunoda, 1988). For the onset of the GD instability in the F-region, an electric field and background gradient of the plasma density are required. The electric field should be of such a direction that the $\boldsymbol{E} \times \boldsymbol{B}$ plasma flow is in the direction of the gradient (e.g. Tsunoda, 1988). This condition is, however, not very restrictive in a sense that a significant difference between the directions of the flow and the density gradient would still support the instability. The electric fields associated with auroral arcs are fairly strong, at least $\sim 5-10 \mathrm{mV} \mathrm{m}^{-1}$ in directions both along and perpendicular to the arc (e.g. Safargaleev et al., 2000; Aikio et al., 2002; Kozlovsky et al., 2007). One would then expect a regular onset of the GD instability and generation of decameter irregularities at the auroral arc edges. 
Clearly, unsatisfactory propagation conditions for HF radio waves are the main factor prohibiting echo detection in the vicinity of the bright optical arcs. One obvious effect is strong radio wave absorption associated with energetic particle precipitation leading to a significant enhancement of the electron density at various heights including the lower E- and D-regions. Another effect of overly strong electron densities is excessive radio wave bending so that no radio wave would penetrate into the $\mathrm{F}$ region. For auroral zone HF radars having a poleward orientation of radar beams, observations are performed in a direction perpendicular to auroral arcs (these are typically stretched in the east-west direction) and the bending effect can be greatly enhanced by a favorable tilt in the ionospheric density contours equatorward of the arc (Uspensky et al., 1993).

Optical observations have shown that relatively narrow bands of luminosity which extended in one direction can also be observed at extreme high latitudes, within the polar cap (e.g. Frey, 2007; Newell et al., 2009). Such bands are often referred to as polar cap (PC) arcs or Sun-aligned (SA) arcs because these, once mapped in geomagnetic coordinates, are typically stretched in the direction toward noon (Sun). The PC/SA arcs are formed by less energetic precipitations (e.g. Frey, 2007; Newell et al., 2009) so that the ionospheric density at their locations is not as high as in the case of auroral zone arcs. The north-south elongation of the PC arcs provides different geometry/propagation conditions for HF coherent radars, such as SuperDARN, because their field of view (FoV) is typically oriented northward. PC arcs are reminiscent of a more global and intense phenomenon of theta aurora. Theta aurora is identified as a luminosity band of up to several hundred kilometers in width extending from the nightside auroral oval to the dayside oval, across the polar cap (e.g. Frey, 2007; Newell et al., 2009). SuperDARN radar studies of theta auroras have been more successful (e.g. most recent paper by Eriksson et al., 2006) because occasional echo occurrence at some ionospheric spots has been sufficient to infer large-scale patterns of plasma flow and discuss the nature of the aurora.

Recent introduction of two new HF radars at Rankin Inlet (RKN) and Inuvik (INV), termed the Polar Dual Auroral Radar Network (PolarDARN) radars, provides opportunities for joint radar-optics work in this sector of the Canadian Arctic. The PolarDARN radars contribute to the SuperDARN effort by supplying data at polar cap latitudes that are not easily accessible for the auroral zone radars. One convenient location for joint optical/radar work is the vicinity of Resolute Bay (RSB), where optical observations are routinely performed with the Optical Mesosphere Thermosphere Imager (OMTI) all-sky camera (Shiokawa et al., 2009) and the PolarDARN radars are able to detect F-region echoes. Koustov et al. (2008) considered one event of RKN observations of a fast moving PC optical form moving duskward on the morning-side. Mostly E-region echoes were detected. The arc correlated with broad-spectra, low-power echoes at the

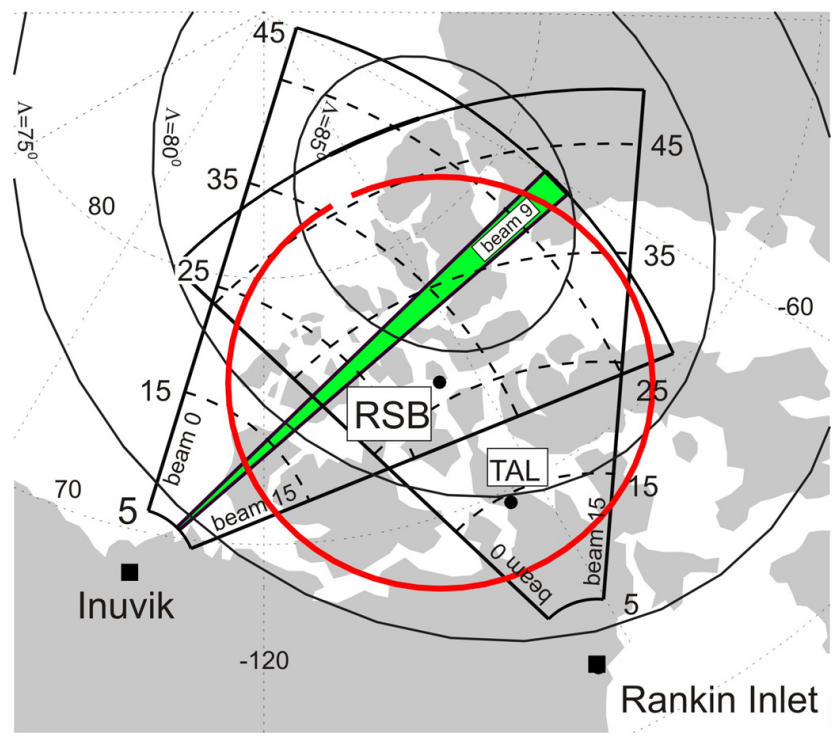

Fig. 1. Field of view (FoV) of the Rankin Inlet and Inuvik PolarDARN radars between range gates 5 and 50. The dashed lines indicate radar ranges according to gate number (5...45). The green sector within the Inuvik radar FoV indicates the orientation of beam 9, the data from which will be discussed in more detail. The red solid circle represents the FoV of the Resolute Bay all-sky camera (for off-zenith angles of $<75^{\circ}$ ) for the assumed 630-nm luminosity height of $250 \mathrm{~km}$. TAL is the location of another all-sky camera, data from which were considered but not presented in this study.

arc location while strong echoes were seen away from the arc. On a very few occasions, F-region echoes at far ranges were detected; they all were seen in the wake of the duskward moving arc, at the side where the conditions for the GD instability were favorable.

In this study, we investigate PolarDARN radar data to show F-region echo signatures of moving PC arcs. We consider data of both PolarDARN radars and optical data from the RSB all-sky camera. We analyze, in detail, data for two PC arcs occurring on 9 December 2007 to illustrate the most common features. Data for additional events demonstrate other interesting signatures including modification of the global-scale convection pattern introduced by the arcs.

\section{Observational geometry of the PolarDARN radars}

Figure 1 shows the fields of view (FoV) of the RKN and INV PolarDARN radars between range gates of 5 and 50. For each radar, the range ticks (dashed line) for gates 15, 25, 35 and 45 (ranges in kilometers can be computed through the equation: range $=180+45 \times$ gate) are given for convenience of viewing. For the events considered, the PolarDARN radars operated in 1-min common scanning mode stepping the radar beam by $3.24^{\circ}$ in azimuth from beam position 0 to beam 

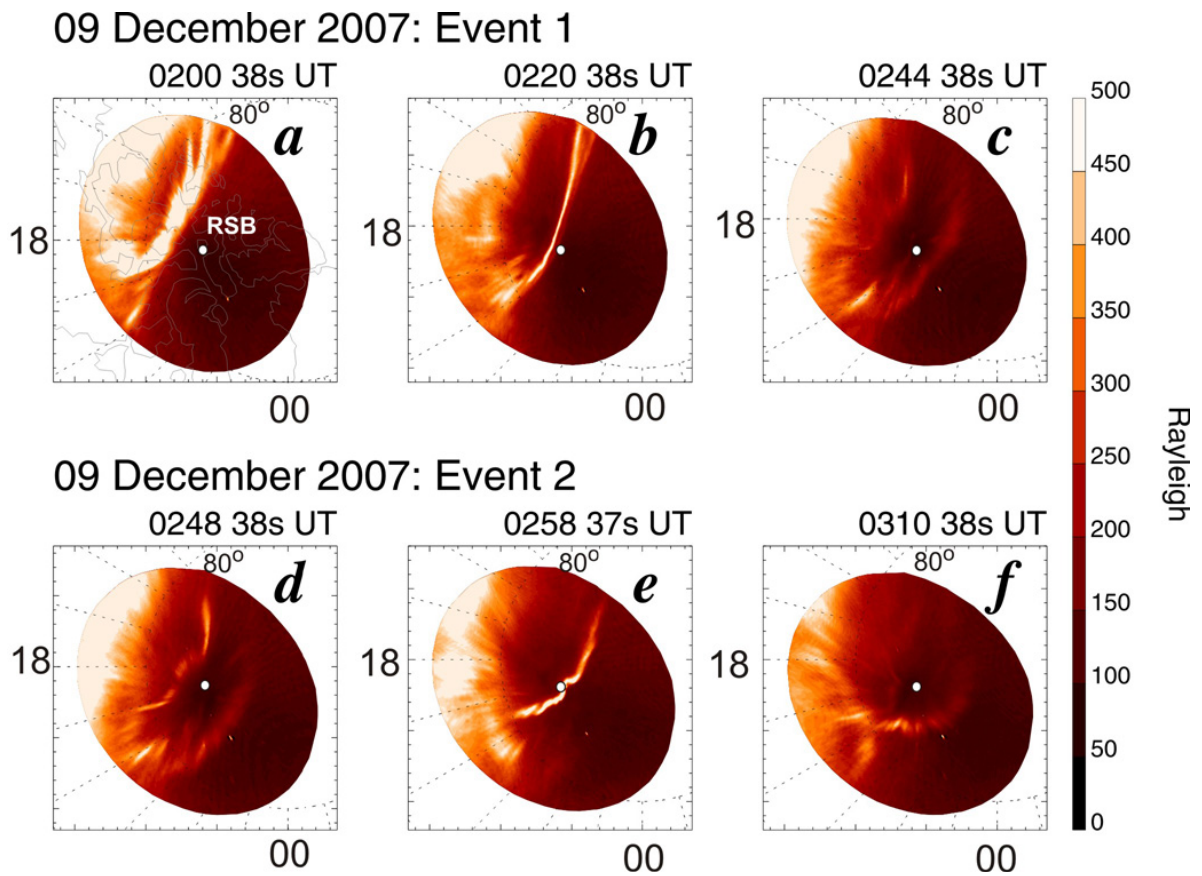

Fig. 2. A series of Resolute Bay all-sky camera images (630-nm emission) showing the progression of polar cap arcs for two events on 9 December 2007. Mapping is done in MLAT-MLT coordinates assuming a luminosity height of $250 \mathrm{~km}$. Panels (a)-(c) and (d)(g) correspond to the events 1 and 2, respectively.

position 15 (beam position 15 to beam position 0 ) for the INV (RKN) radar. Positions 0 and 15 are indicated in Fig. 1 for both radars. In this study, data from INV beam 9 (green sector within the INV FoV in Fig. 1) and central beams from the RKN radar will be discussed in more detail. The integration time was $3 \mathrm{~s}$. The radars measured echo power, Doppler velocity and spectral width in each $45-\mathrm{km}$ range gate.

Figure 1 also shows the FoV of the RSB all-sky camera for the off-zenith angle of $75^{\circ}$ and assumed luminosity height of $300 \mathrm{~km}$. In this study we considered data in the red line $(630 \mathrm{~nm})$. RSB zenith is away from the RKN (INV) location by 27 (30) radar gates. The RSB all-sky camera has a temporal resolution of $2 \mathrm{~min}$, with an exposure time of $30 \mathrm{~s}$. For comparison with radar data, optical images closest in time to radar measurements were selected.

According to Fig. 1, the RSB camera seems to be optimal for joint work with the PolarDARN radars for range gates 15-40, corresponding to radar slant ranges of $\sim 850$ $2000 \mathrm{~km}$. Unfortunately, statistically speaking, the number of echoes in gates above $20-22(\sim 1000 \mathrm{~km})$ drops significantly, although a reasonable amount of echoes can still be detected (Liu, 2010). To identify joint events, we manually searched through all optical data collected in 2007-2010 and selected 20 PC arc events. In this paper we selected one event, 9 December 2007, for detailed analysis and illustrate additional features by presenting data for other events.

For the 9 December 2007 event we focus on a relatively short period of $\sim 2 \mathrm{~h}$ duration between 01:30 and 03:30 UT
(18:30-20:30 MLT for the RSB location). During this period, two separate PC arcs developed and progressed through the FoV. Each arc appeared at the duskward (western) edge of the RSB camera FoV detaching from the auroral oval luminosity band, then it moved poleward (dawnward) toward the RSB zenith, reached it, slowed down, weakened and eventually disappeared.

\section{Detailed analysis of the 9 December 2007 data}

9 December 2007 was a geomagnetically quiet day with the Kp index of 1o between 00:00 and 03:00 UT and of 1- between 03:00 and 06:00 UT. The previous day was the quietest day of the month. There was little magnetic activity in the sector of PolarDARN observations. The arcs occurred under slightly negative interplanetary magnetic field (IMF) $B_{\mathrm{z}}$ varying between -1 and $-5 \mathrm{nT}$ and negative IMF $B_{\mathrm{y}}$ varying between -2 and $-4 \mathrm{nT}$.

\subsection{Optical data}

Figure 2 gives examples of the observed PC arcs. For all frames the luminosity was mapped in MLT-MLAT coordinates assuming a luminosity height of $250 \mathrm{~km}(630-\mathrm{nm}$ filter data). We note that all diagrams with optical images to follow were produced with mapping under the same assumption and on all diagrams a large dotted circle corresponds to 


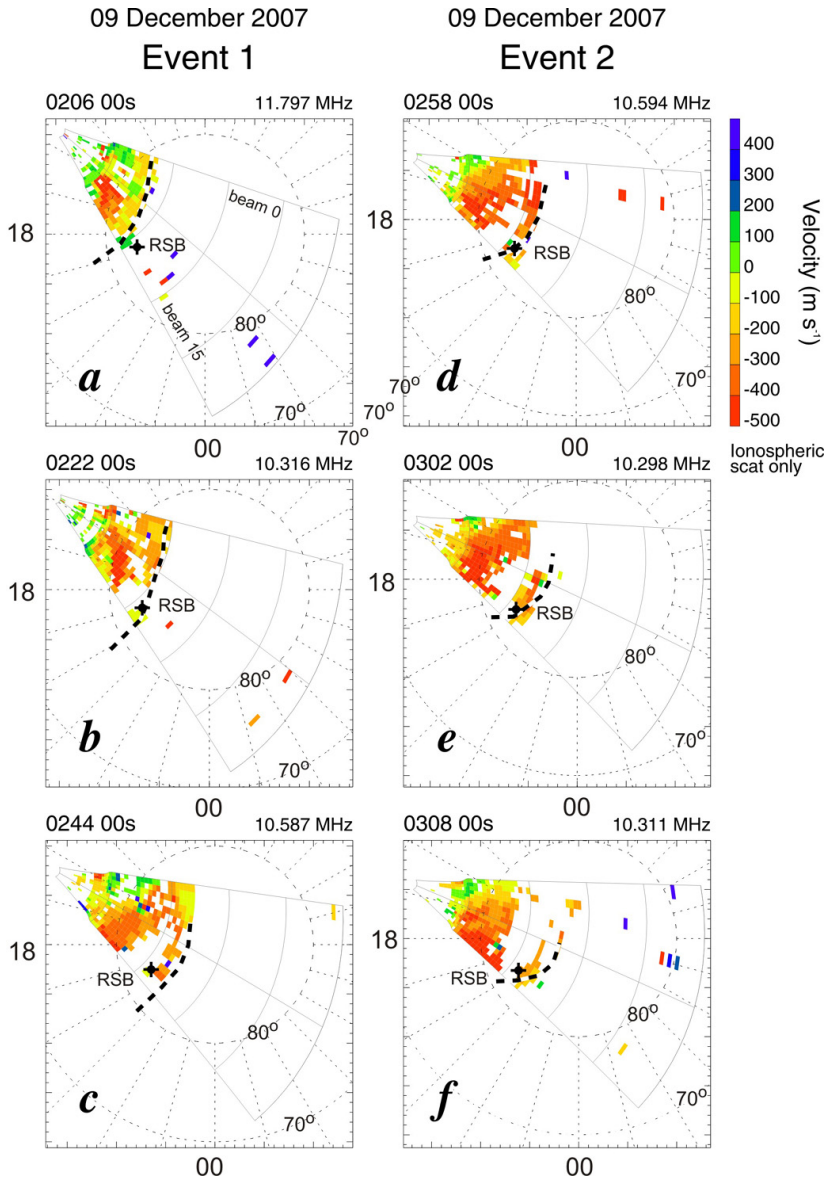

Fig. 3. A series of Inuvik radar velocity maps recorded on 9 December 2007. Mapping is done in MLAT-MLT coordinates. Range ticks within the radar field-of-view correspond to gates 15, 30, 45 and 60. Dashed lines indicate locations of the polar cap arcs. Panels (a)-(c) and (d) $-($ g) correspond to the events 1 and 2, respectively.

MLAT $=80^{\circ}$ while sector-like dotted lines denote the MLT lines separated by $1 \mathrm{~h}$.

In Fig. 2, both arcs detached from the poleward edge of the auroral oval in the afternoon sector. The auroral oval luminosity is well seen at the edges of all images. It was much stronger and located at higher latitudes prior to $\sim 01: 00 \mathrm{UT}$. There were some dynamical changes within the oval, as indicated by the RSB camera as well as the U of Calgary imager located at Toloyak (TAL), at lower latitudes, Fig. 1 (actual data are not presented here). For the period under investigation, some azimuthal (eastward) luminosity expansion of the auroral oval luminosity was seen in the RSB data, as indicated by the luminosity distribution in Fig. $2 b$ and $c$.

The first arc (event 1) was clearly visible starting from 01:56 UT. It was aligned with multiple luminosity bands excited at $\sim 01: 50$ UT along the poleward edge of the auroral oval. Figure 2a shows an image of a well seen optical form with intensity of $\sim 500 \mathrm{R}$ detached from the auroral oval. At this time, the form is "connected" to the auroral oval at its most equatorward side, at 19:00 MLT. The form was moving toward the RSB zenith indicated by a white dot on all frames of Fig. 2. In $\sim 10 \mathrm{~min}$, the form changed its shape to look more like a thin arc of the comparable optical intensity. Figure $2 b$ shows the arc located close to the RSB zenith. By this time, it started weakening. While continue its motion, the arc became more diffuse in nature, decreasing significantly in optical intensity after $\sim 02: 44$ UT, Fig. 2 c. Together with the arc progression, the luminosity at the poleward edge of the auroral oval expanded toward the pole as well so that the edge of the weak luminosity (of 300-400 R) moved much closer to RSB, Fig. 2c.

The bottom row of Fig. 2 illustrates development of the second arc (event 2). The arc detached from the expanded (toward the pole) weak-luminosity poleward edge of the auroral oval. The second arc had about the same orientation as the first arc but it was not as strong, just above the background luminosity of 300-400 R. Figure $2 d$ shows as the first and second arcs, being both weak and diffuse at this time (with optical luminosity of 350-450 R), co-exist with a spatial separation of $\sim 500 \mathrm{~km}$. About $10 \mathrm{~min}$ later, the second arc reached the RSB zenith (Fig. 2e). By this time, it became stronger, $\sim 500 \mathrm{R}$, with a wave-like structure in its central part. The arc was existing for another $\sim 10 \mathrm{~min}$ (Fig. $2 \mathrm{f}$, optical intensity $\sim 250-350 \mathrm{R}$ ) progressing toward the pole (dawn sector). The second arc was moving faster than the first one; it reached the RSB zenith faster (10 min versus $20 \mathrm{~min})$. In the frames to follow, for comparison with PolarDARN radar data, the arcs' location will be denoted by a dashed line representing regions with strongest luminosity.

\subsection{INV and RKN radar data}

Radar signatures of the arcs were seen in 2-D maps of the INV and RKN echo parameters: power, velocity and spectral width. Figure 3 shows velocity maps for the INV radar observations, three selected frames for each event. We note that the selected frames are not exactly for the same moments as in Fig. 2. This has been done to better illustrate radar signatures of the arcs. MLT-MLAT coordinates were used with a full circle corresponding to MLAT $=80^{\circ}$. Within the radar FoVs, range gate marks of 15, 30, 45 and 60 as well as the boresight direction (a line through the middle of the FoV) are shown. For event 1, left column, isolated regions of echoes (more obvious in beams 7-15) depart from the larger echo area and progress toward the magnetic pole (center of the dashed circle). We note that the polarity of the echo velocity in the arc vicinity is negative (red to yellow colors). This implies ionospheric irregularity motion away from the radar, consistent with echo patch motion away from the radar. On the first frame at 02:06 UT, a distinct yellow patch of the velocity at near arc locations (beams 8-14) is quite different from the red-green color in the rest of the echo regions surrounding the patch. A matched plot for the echo power (not presented here) does not show such a separate patch so 
that the echo velocity map has an advantage in identification of the arc-associated echoes. On the next two frames, one can see the distinct patch of backscatter trails the arc and is always in its wake. For event 2, the arc-associated echo band occurred off the main echo region (Fig. 2d) in accordance with appearance of a weak luminosity band poleward of the main auroral oval, as discussed above (see Fig. 2c). The echoes were trailing the second arc (Fig. 3e, f) while it was moving toward the magnetic pole.

To identify and compare signatures of the first arc in the radar data for both systems, Fig. 4 presents the power, velocity and spectral widths of INV and RKN echoes for a scan starting at 02:34 UT. For INV (Fig. 4a-c) the arc-associated echoes constitute a distinct echo patch stretched along the arc (beams 7-15). The echo patch is separated by a gap from a large region of background echoes at shorter ranges. The echo patch is located in the wake of the (moving) arc with the power being stronger in low numbered beams (beams 1-6), Fig. 4a. Lower power in larger numbered beams is perhaps due to farther ranges of the echoes here (power decreases as $\left.1 / r^{3}\right)$. The Doppler velocity is not uniform along the echo patch extent; it is slightly larger in the lower numbered beams, Fig. 4b. Analysis of the all-sky images showed that this part of the arc was moving slightly faster so that the arc was experiencing the rotational motion with the side closer to the auroral oval moving slower than the "outer" side. The maximum Doppler velocities of the arc-associated echoes are $\sim 300 \mathrm{~m} \mathrm{~s}^{-1}$. The spectral width of the arc-associated echoes, Fig. $4 \mathrm{c}$, is not very large as compared to the background echoes at shorter ranges, especially in the low-numbered beams. On the other hand, a number of gates in the central part of the echo patch have enhanced widths of up to $\sim 200 \mathrm{~m} \mathrm{~s}^{-1}$.

For the RKN radar, signatures of the arc for this specific time are easier to recognize in the power and spectral width plots, Fig. 4d, f. The power is strongly enhanced in the arc's wake, although some echoes are seen in front of the moving arc as well. The number of echoes at the arc location is decreased, Fig. 4d, a feature that has been identified as the arc signature in the E-region echoes (Koustov et al., 2008). Interestingly enough, although both the RKN and INV radars see enhanced echo power in the wake of the arc, the echoes do not overlap so that the radars have their own areas of favourable echo detection. We note that this is quite a common feature in this and other events.

The RKN spectral width of arc-associated echoes (seen in close vicinity of the arc) was large, certainly larger than the width of the background echoes, Fig. 4f, red color versus green and blue, respectively. We noticed that broad echoes in the wake of a moving PC arc is a more typical situation in other events, and one example will be given later. Regarding the broader RKN echoes as compared to the INV echoes it should be pointed out that the INV radar frequency was $10.6 \mathrm{MHz}$ while the RKN radar frequency was $12.5 \mathrm{MHz}$. Ponomarenko and Waters (2006) established that echoes at

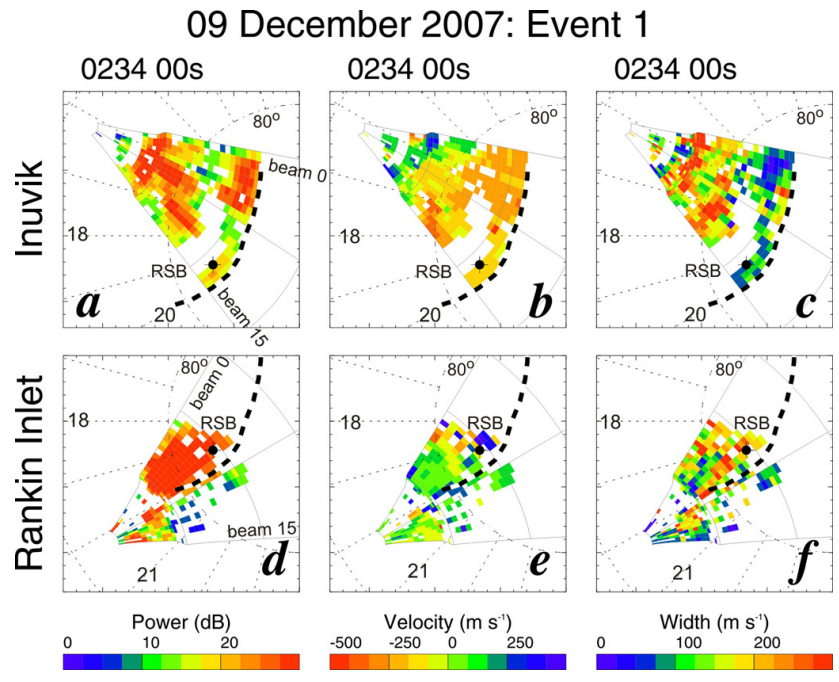

Fig. 4. (a)-(c) Inuvik and (d)-(f) Rankin Inlet radar maps of the echo power, velocity and spectral width for the scan which started at 02:34 UT (event 1). Mapping is done in MLAT-MLT coordinates. Range ticks within the radar field-of-view correspond to gates 15 , 30, and 45. Dashed lines indicate locations of the polar cap arc.

lower radar frequency have typically smaller spectral width. In our case, the expected reduction factor of $\sim 1.2$ allows the INV spectral widths to be similar in magnitude to the RKN spectral width. This reduction factor can, however, still not explain the larger spectral width $\left(>200 \mathrm{~m} \mathrm{~s}^{-1}\right)$ observed.

The RKN velocity map of Fig. 4e is fairly complex. One can notice a yellow distinct echo patch at the far edge of the echo region (low number beams 0-3) while everywhere else the color is green implying plasma motion toward the radar. The yellow echo patch is perhaps a signature of the arc; this velocity color persistently correlates with the arc's wake in many other frames for event 1 and some maps show stretching of the yellow color along the arc extent. But at 02:34 UT, as shown in Fig. 4e, the arc was weak, and perhaps the arcassociated flow was decreased and overpowered by the background flow that was predominantly toward the radar (away from magnetic noon toward midnight). If the RKN and INV velocities are combined (assuming that the echoes are at the same MLATs and MLTs), the resulting merged velocities would indicate that the overall general convection direction was toward the magnetic pole, as velocities observed by the INV radar were much larger than the velocities measured by the RKN radar.

\subsection{HF echo progression along INV fixed beam and across RKN FoV}

To give other perspectives on arc-associated echoes we consider the INV echo velocity in beam 9 versus time and the RKN echo power distribution versus beam number (radar azimuth) for gate 26 at various UT times. 


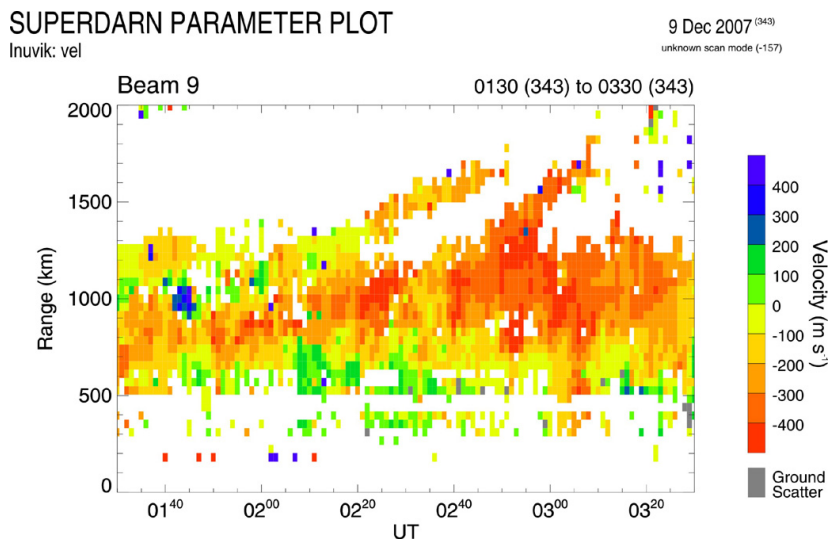

Fig. 5. Range-time-velocity plot for the Inuvik radar observations in beam 9 on 9 December 2007 between 01:30 and 03:30 UT.

Figure 5 shows the range-time-intensity plot for the INV velocity. Arc-associated echoes are easily recognizable here as two "fingers" emerging from the band of echoes. This pattern of echo occurrence is expected because the arcs were progressing radially away from the INV radar location, along its central beams. The first (second) finger starts at $\sim 02: 10$ (02:50) UT. The second finger/echoing region has a larger slope indicating a faster speed of progression. Doppler velocities of echoes for the first (second) arc are up to $\sim 200$ (400) $\mathrm{m} \mathrm{s}^{-1}$.

Figure 6 gives the RKN power distribution for several individual radar scans along with the luminosity distribution (as obtained by the OMTI camera) for each scan, three plots for each event. Radar range gate 26 (corresponding to a radar range of $1350 \mathrm{~km}$ ) was considered. One can see that the echo power is maximized in lower numbered beams, implying that the echoes were located in the wake of progressing luminosity maxima (arcs). This is particularly well seen on the frame for 02:10 UT. On the next two frames for event 1 the arc/luminosity maximum shifts to larger beam number and the echo region follows the arc. For event 2, the luminosity maxima were not as strong, but stronger echo power in its wake was seen as well.

\subsection{Propagation speeds of optical and radar features. CADI $E \times B$ drifts}

Now we focus on the arcs' and their radar counterparts' progression speeds and the $\boldsymbol{E} \times \boldsymbol{B}$ drifts that we infer from optical measurements, radar Doppler velocities and CADI ionosonde drift measurements at Resolute Bay. The RSB CADI instrument is a digital ionosonde capable of measuring the angle of arrival and velocity of radio reflections from blobs with enhanced electron density in the $\mathrm{F}$ region (e.g. Grant et al., 1995). By combining velocities from a large number of individual reflectors (ideally more than 50-100) and knowing the location of each reflector, the average mag- nitude and azimuth of the blob motion $(\boldsymbol{E} \times \boldsymbol{B}$ drift $)$ is inferred for the near zenith location.

As mentioned, the arcs exhibited a complex motion consisting of a shift toward the magnetic pole as well as a slow overall clockwise rotation. We would like to ignore this detail and concentrate on typical speeds of the arcs' motion in their central parts that were predominantly shifting outwards along INV beam 9.

First, we consider velocities measured by optical means. Simple estimates from arc locations shown in Fig. 3 give an average speed of the arcs poleward progression of $\sim 200 \mathrm{~m} \mathrm{~s}^{-1}$ for the first arc and $\sim 450 \mathrm{~m} \mathrm{~s}^{-1}$ for the second arc. A more elaborate analysis was done following the method of Hosokawa et al. (2006). In this approach, changes in the luminosity are traced over subsequent frames in a number of points around the zenith of the RSB camera. This provides an apparent velocity of optical form motion in up to 25 points. We consider here an average value of the velocity magnitude and azimuth. Figure $7 \mathrm{a}$ is a keogram of the luminosity variations across the north-south line of the all-sky imager. The zenith positions of the arcs are shown by time markers (dashed line). Both arcs are clearly identifiable in Fig. 7a. The velocity magnitude and azimuth are shown in Fig. 7b, c. The concurrent data by the CADI ionosonde are shown by blue plus signs.

According to both instruments, the flow velocity was not relatively constant, especially while the arcs were close to the zenith. Some of the variability, without doubts, originated from deficiencies of the instruments for measurements in such a delicate situation. Our goal, however, is to make an assessment of typical/average velocities outside the arcs. To accomplish this, we first established the time for the arcs' location at the RSB zenith. All-sky images gave us times of 02:22 UT and 02:58 UT for event 1 and 2, respectively; this is very close to what one sees in Fig. 7a. Since the optical measurements become sensitive to the arc arrival several minutes before it actually arrives to the zenith (due to data collection from 25 points spatially separated on the sky), we infer that the average plasma velocity on the dusk side of the arc 1 (arc 2) was $250(400) \mathrm{m} \mathrm{s}^{-1}$. On the dawnside of the arc 1 (arc 2), the average velocity was $\sim 100-200(250) \mathrm{m} \mathrm{s}^{-1}$. The velocity of luminosity motion "inside" the arc is difficult to determine as optical data are spatially integrated. The optical data in Fig. 7b show very large values of $\sim 400 \mathrm{~m} \mathrm{~s}^{-1}$ for the near zenith locations; we believe these values do not reflect the real plasma motion as some luminosity re-distribution along the arcs was seen. In terms of the velocity magnitude, the CADI data are consistent with estimates from the optical data except of much larger variability, which is expected. In addition, the CADI data were not as frequent as they would normally be and they have large uncertainty (several tens of $\mathrm{m} \mathrm{s}^{-1}$ ) for the entire period considered.

In terms of the plasma flow azimuth, there is an offset between the instruments especially for the near zenith arc locations. Away from these times, the flow azimuths were 


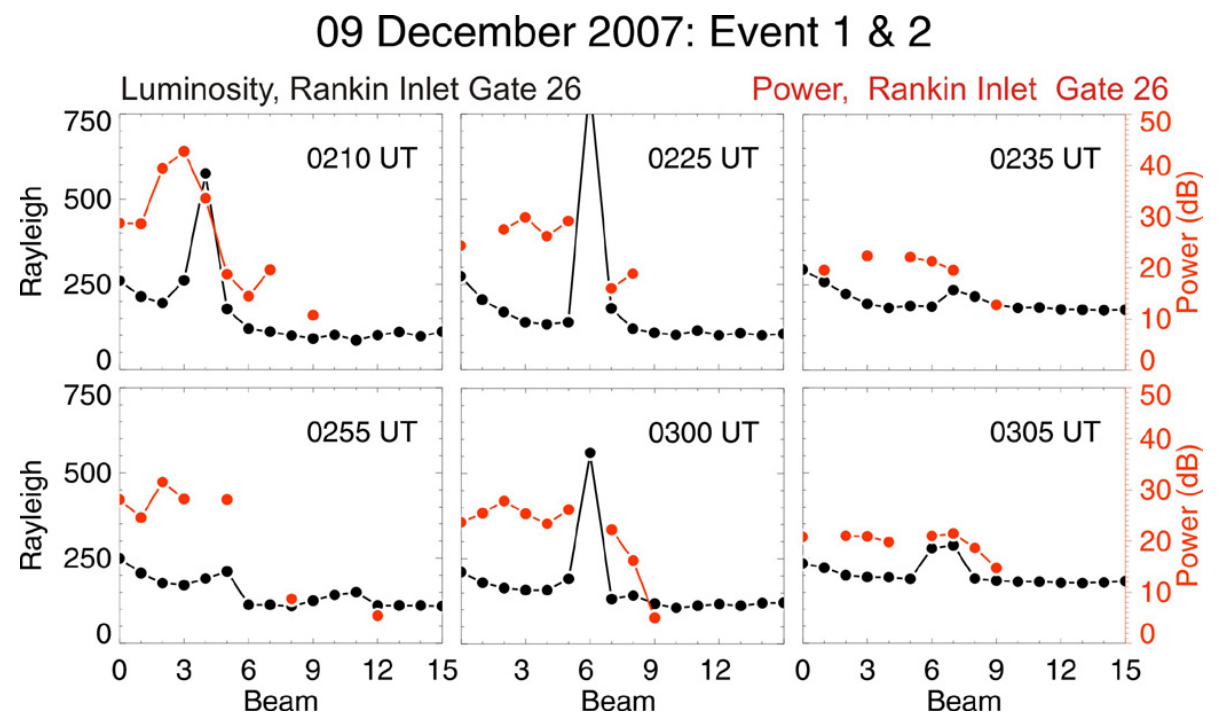

Fig. 6. A series of plots showing azimuthal distribution of the Rankin Inlet radar echo power (red) and auroral luminosity intensity (black) at the radar range gate 26 . The top (bottom) sequence corresponds to event 1 (event 2).

$\sim 90^{\circ}-110^{\circ}$ implying that the flow was predominantly antisunward (the azimuth for both instruments was counted from geographic North).

The speed of the INV radar echo region poleward motion (progression along the beam) can be determined from the slopes of the "fingers" on the range-time-velocity plots similar to those shown in Fig. 5. By considering data in all beams, we found that the average speed of the echoing region motion was $225 \pm 2 \mathrm{~m} \mathrm{~s}^{-1}$ for event 1 and $401 \pm 4 \mathrm{~m} \mathrm{~s}^{-1}$ for event 2 . These numbers are very close to those inferred from optical and CADI data.

Finally, the INV Doppler velocity measurements allow us to estimate the component of the $\boldsymbol{E} \times \boldsymbol{B}$ plasma flow along each of the beams. As one can infer from the data presented, for example Figs. 3-5, the Doppler velocity was changing all the time, but within certain limits. We computed the median Doppler velocity for arc-associated echoes in beam 9 (corresponding to "fingers" in Fig. 5). For event 1 (event 2) it was found to be $-235(-357) \mathrm{m} \mathrm{s}^{-1}$. We note that the velocity did not decrease as the arcs (and their radar signatures) were weakening. This is similar to observations by Safargaleev et al. (2000) who reported even some increase of the drift perpendicular to an arc (electric field tangential to the arc) just prior to the arc disappearance.

Presented estimates of the speed of the PC arcs' poleward progression, radar echo regions and $\boldsymbol{E} \times \boldsymbol{B}$ plasma drifts inferred from CADI and INV Doppler data (the major component of the total drift) are consistent. This allows us to conclude that both optical arcs were moving with velocities close to the $\boldsymbol{E} \times \boldsymbol{B}$ plasma drift of the F-region plasma.

\section{HF radar signatures of $\mathrm{PC}$ arcs in other events}

Presented data highlight typical features in the PolarDARN radar echoes accompanying PC arcs. Here we illustrate some other peculiar features that have been noticed in other events.

\subsection{Importance of power maps}

First of all, it is worth noting that not all PC arcs had radar echoes in their vicinity even though some of the arcs were bright and were passing the RSB zenith. We attribute this to unsatisfactory propagation conditions for radar waves. Typically only one of the radars (either RKN or INV) detects a significant amount of echoes. We found that INV (RKN) was more successful in monitoring dusk/afternoon (dawn/morning) arcs. In many cases considered, the arc appeared at ranges where the background echoes existed prior to the arc onset so that only minor changes in the echo power were detected. In these cases, it was difficult to identify specific echoes associated with the arcs. We illustrated in Fig. 3a that the velocity maps could be helpful in distinguishing the arc-associated echoes from the background ones. But often the power maps were more helpful. Figure 8 gives such an example for the event of 20 December 2008. Here for maps at 02:04 UT, the power distribution on Fig. 8b hints that the arc can be along the poleward edge of the strong echo power region (where it is actually was located). The velocity map, Fig. 8c, indicates a "channel" with small positive velocities (green and blue colored region in beams 5-9 surrounded by red and yellow colored regions), and the channel correlates with the arc location. Positive velocity indicates a sunward flow that could be considered as a signature of the $\mathrm{PC}$ arc. For this moment, the velocity map is instructive in 


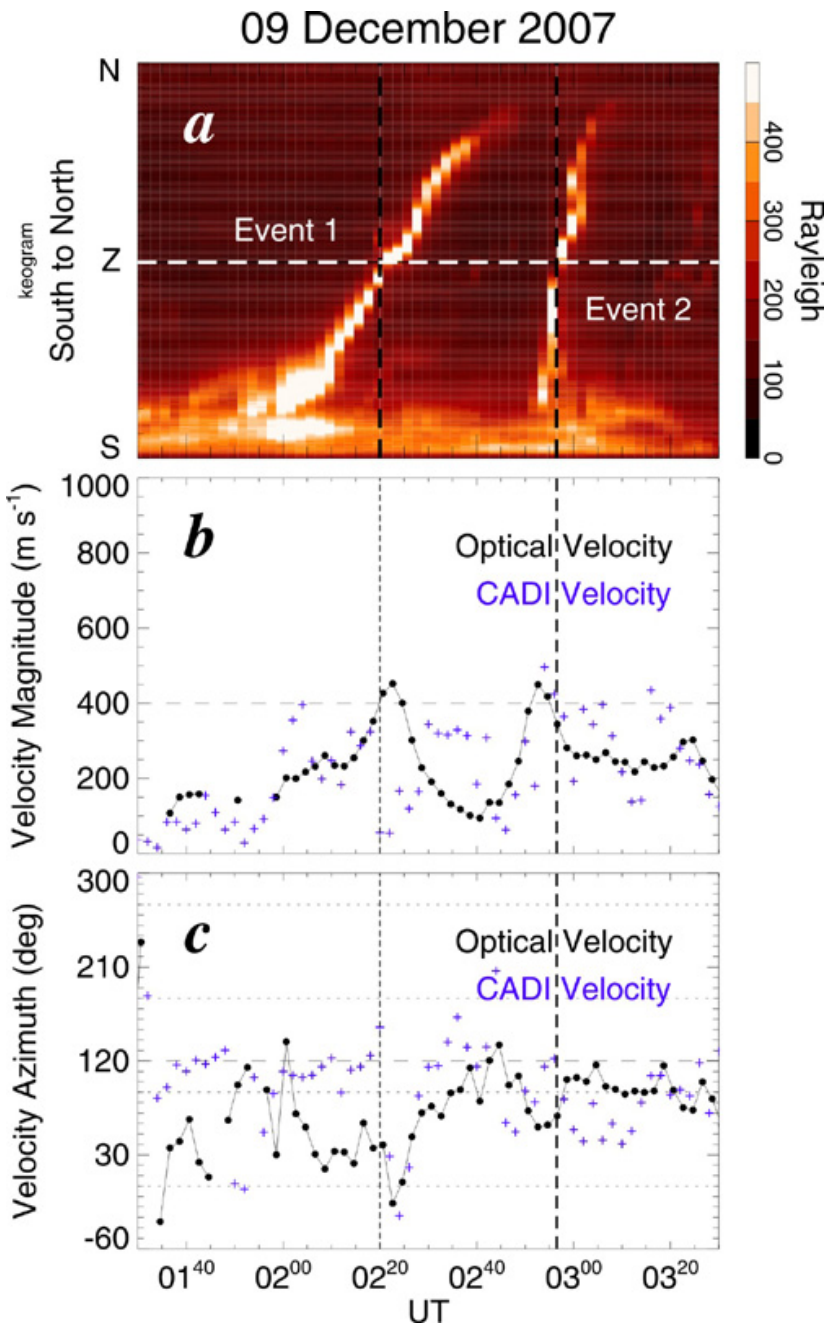

Fig. 7. (a) A keogram of auroral luminosity in the north-south direction, the (b) speed and (c) azimuth of the auroral patch motion (black) as inferred from the Resolute Bay all-sky camera measurements. The velocity vector estimates were done by the method of Hosokawa et al. (2006). Blue crosses on panels (b) and (c) are the $\boldsymbol{E} \times \boldsymbol{B}$ plasma velocity magnitude and azimuth, respectively, according to the Resolute Bay CADI ionosonde.

the selection of the likely position of the PC arc. The situation changes for the frame of 02:08 UT, just 4 min later, Fig. 8e, f. Here the arc-associated power enhancement is "extending" from the large echo region (beams 12-14) and the "background" echo band is seen at closer ranges to the radar. For this moment, the velocity map does not have a strong evidence for the arc location (no channel), especially if one expects the sunward flows associated with it (the velocity is actually away from noon at the arc location, especially in the high number beams).

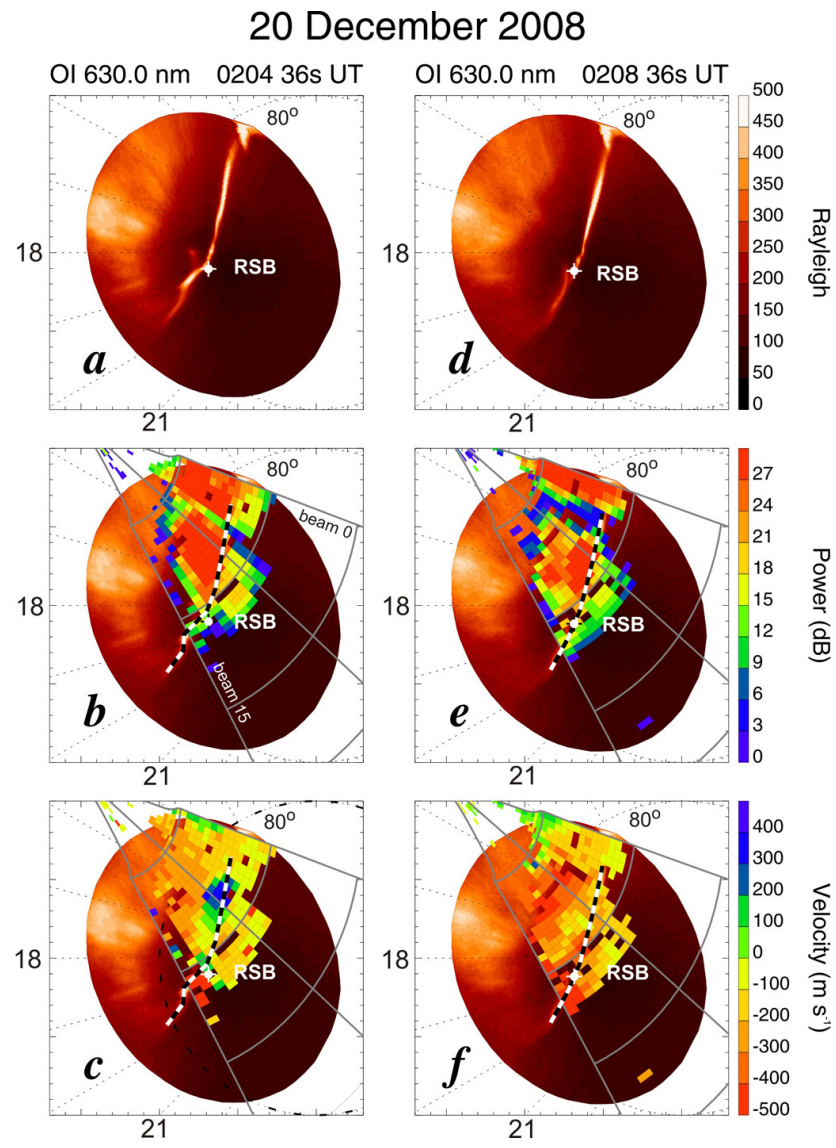

Fig. 8. Resolute Bay all-sky camera images of the polar cap arcs on 20 December 2008 at (a) 02:04 and (d) 02:08 UT. Mapping is done in MLAT-MLT coordinates. (b) and (e) Inuvik radar power maps and locations of the polar cap arc (dashed lines). (c) and (f) Inuvik velocity maps and locations of the polar cap arc (dashed lines). Range ticks within the radar field-of-view correspond to gates 15 , 30,45 and 60 .

\subsection{Arc-associated reversals in plasma flows}

The examples of the INV radar observations on 20 December 2008 (Fig. 8) and the data of Fig. 4e hint that PC arcs are not always correlated with reversals in the flow as reported previously by other instruments (e.g. review by Zhu et al., 1997). This could be because the arc-associated flows co-exist with the background plasma flow controlled by the IMF (and other factors) so that the total plasma drift vector can be oriented at some azimuthal angle with respect to an arc. This angle is generally different on opposite sides of an arc. Since a coherent radar measures only the line-of-sight component of the $\boldsymbol{E} \times \boldsymbol{B}$ drift and the spatial resolution is not great, depending on the geometry of observations, it may not see a well-defined velocity reversal in the $\mathrm{PC}$ arc vicinity. In addition, flows near PC arcs are often patchy (Gallagher, 1997). 
Figure 9 is one fortunate event on 20 March 2009 when the PC arc was moving duskward (to the left in Fig. 9) being stretched along the central beams of the RKN radar (or the boresight direction represented by a straight line throughout the RKN FoV). In this case, as the arc was passing the central beams, the contribution to the measured Doppler velocity from plasma flow across the arc extent was minimal and the velocity reversal was possible to detect.

For this event, in terms of the echo power distribution around the arc, the data are consistent with previously reported results. F-region echoes were observed in the wake of the arc, in radar beams 8-14 and gates 30-45, similar to the examples of Figs. 3, 4 for the event of 9 December 2007. Echoes also existed in short-range gates of $<15$ for almost all beams. Some of these were probably F-region echoes (range gates $>10$ ) while others were E-region echoes (range gates $<10$ ). For all range gates between 0 and 15 , there was an echo power drop in beams $8-10$ which correlated with the leading edge of the duskward moving arc. An echo power gap near the arc location is very similar to the report by Koustov et al. (2008) for another case of a moving PC arc.

The velocity map of Fig. 9c shows that the plasma flow at the far ranges, in range gates 30-45 and dawnward of the arc, was toward the radar (blue color, positive) with a magnitude above $500 \mathrm{~m} \mathrm{~s}^{-1}$. The velocity of echoes in central beams $6-8$ and in smaller range gates of 10-15 (probably F-region echoes as well) was away from the radar (yellowbeige colors, negative). In this region velocities were up to $300-400$; these were not significantly smaller than the velocity of the far-range echoes. Smaller velocity magnitudes on the duskside of the arc can be attributed to the expected antisunward component of the background flow along the arc (in addition to the background flow component perpendicular to the arc). Thus, the RKN data demonstrate opposite direction and a comparable magnitude of the plasma flows on opposite sides of the arc, as expected. We note that the velocity data in the smallest gates of 0-10 did not show the reverse of the flow on the dusk side of the arc (green color, flow toward the radar). We relate this to the fact that the arc was weaker in its most equatorward part and that the intensity of the arcassociated flow was probably also weaker. At these ranges, the Doppler velocity measured was strongly affected by the background flow which was antisunward and duskward.

For other events considered, PC arcs were usually oriented at some angle with respect to the PolarDARN radar beams, and the velocity reversals were difficult to detect. One interesting observation is presented in Fig. 10. Figure 10, for the event of 7 November 2007 (additional information on this case can be found in Liu, 2010), shows the optical arc and distribution of (b) power, (c) velocity and (d) spectral width for the scan started at 09:56 UT. According to Fig. 10b, the echo power is enhanced at ranges about $100-300 \mathrm{~km}$ closer to the radar than the arc location, consistent with observations by Uspensky et al. (2001) and Séran et al. (2009) in the auroral zone. We should mention that echoes in the most clock-

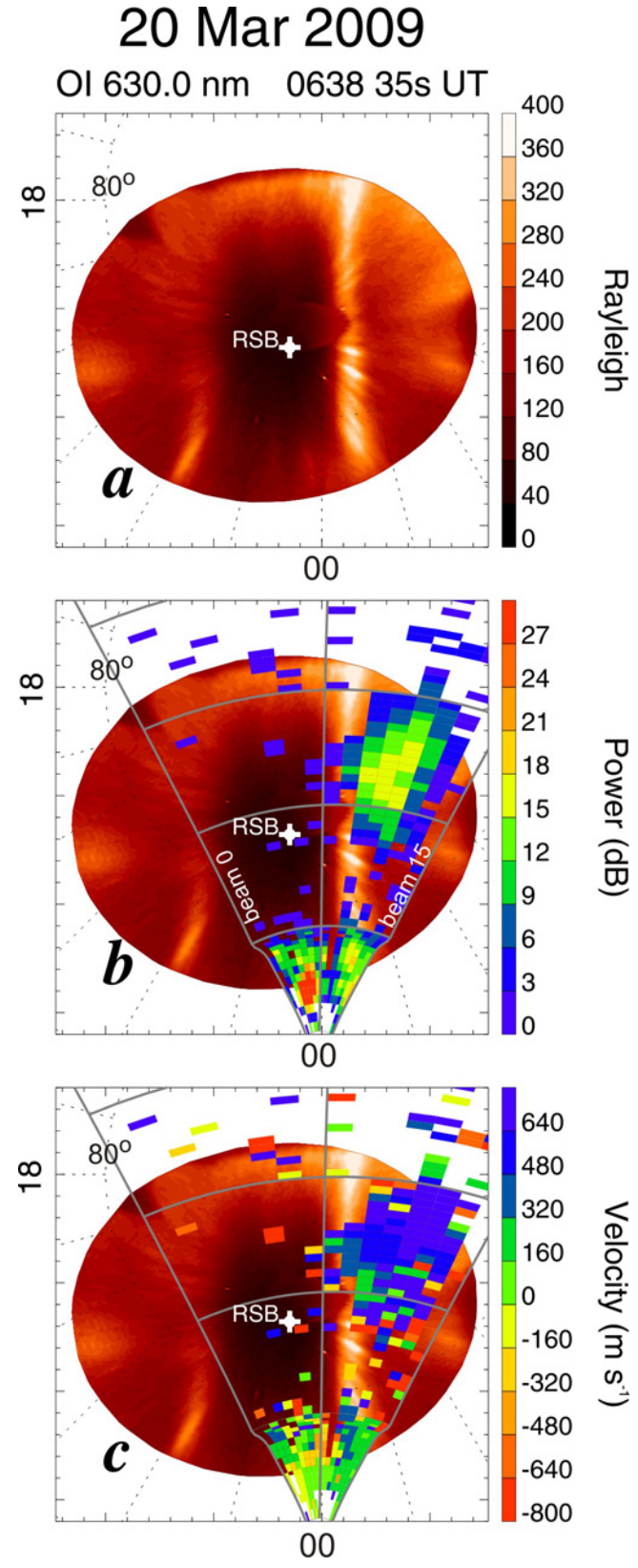

Fig. 9. (a) Optical image of the polar cap arc for the event of 20 March 2009, 06:38 UT. Mapping is done in MLAT-MLT coordinates. Panels (b) and (c) show the same image with overlaid Rankin Inlet radar maps of the echo power and velocity, respectively. Range ticks within the radar field-of-view correspond to gates 15, 30, 45 and 60 .

wise beams $12-15$ are quite away from the arc, and the pattern of echo distribution suggests that these echoes are related to the poleward edge of the auroral oval. It is very likely that the radio wave propagation conditions were not satisfactory for echo detection closer to the arc in these beams. Doppler velocity data of Fig. 10c confirm our expectation regarding the nature of the echoes in beams $12-15$. The velocity here 


\section{November 2007}

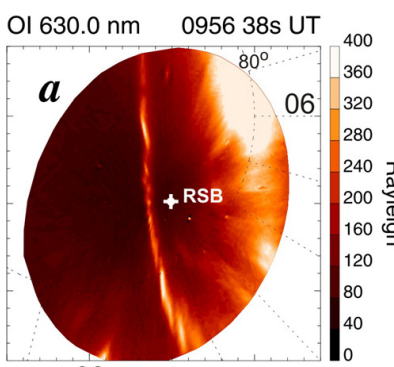

00

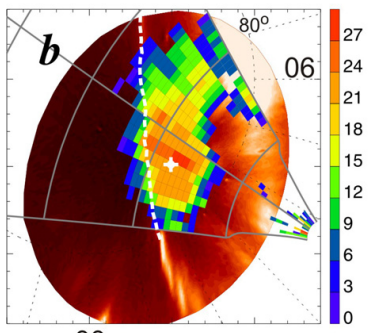

00

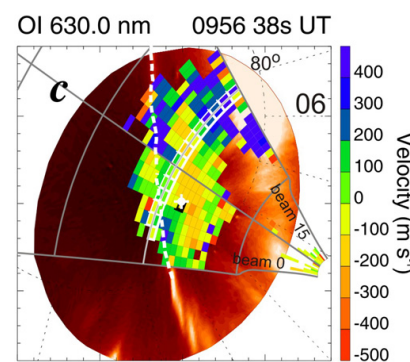

00

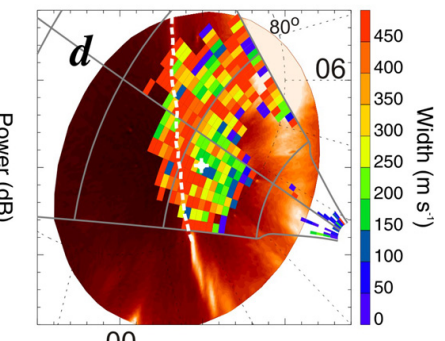

00

Fig. 10. (a) Optical image of the Resolute Bay all-sky camera on 7 November 2007 at 09:56 UT. Panels (b), (c) and (d) show the same image with overlaid concurrent Rankin radar maps of the echo power, velocity and spectral width. Mapping is done in MLATMLT coordinates. The arc location in panels (b)-(d) is shown by dashed lines. In panel (c), the edges of the radar gates 29 and 30 are enhanced by white lines. Range ticks within the radar field-of-view correspond to gates $15,30,45$ and 60 .

is strongly positive as compared to the velocities in beams 911. The velocity distribution for the echoes in the arc vicinity is quite peculiar. The farthest echoes located duskward of the arc have negative velocity. Close to the arc and at the arc location, the velocity is positive. Closer to the radar, dawnward from the arc, the velocity is again negative. The band of negative velocity is quite stretched parallel to the arc giving an impression that the band and the arc might be related.

\subsection{Spectral width of arc-associated echoes}

Analysis of a number of events showed that the spectral width of arc-associated F-region echoes is often enhanced. The case of Fig. 10d is a very representative one. One can clearly see that a band of broad-spectrum (widths up to $400 \mathrm{~m} \mathrm{~s}^{-1}$ ) echoes extends all along the arc. This result is consistent with broad-spectrum E-region echoes correlating with arc locations as reported by Koustov et al. (2008). We should also mention the existence of a distinct echo patch with broad echoes in beams 13-15. This echo patch correlates with the edge of enhanced luminosity at the poleward edge of the auroral oval. Notice that all other echoes have smaller widths (less than $200 \mathrm{~m} \mathrm{~s}^{-1}$ ), which is indeed typical for the extreme high latitudes (Villain et al., 2002).

\section{Arc signatures in global-scale convection patterns}

PC arcs are expected to modify the overall convection pattern (e.g. Zhu et al., 1997; Newell et al., 2009). Such modifications should be seen in SuperDARN global-scale convection maps as mesoscale features. Unfortunately, over the last several years of low solar activity there were fewer echoes from the radars at lower (auroral) latitudes (e.g. Liu, 2010) so that data from the polar cap PolarDARN radars played a major role in producing convection maps. This provides a challenge in identifying convection restructuring due to $\mathrm{PC}$ arcs onset as the data are fit using the statistical model (Ruohoniemi and Baker, 1998). It is not a surprise that many convection maps for the PC periods are too complex to make a confident judgement. In this section we show some features that might represent the real situation.

We first consider data for our major event of 9 December 2007. Figure 11a shows the convection pattern for a moment when the arc was well detached from the oval and moving toward the magnetic pole. The arc was near the convection reversal of the global dusk-side convection cell. In more details, one can notice two potential minima represented by two circular regions: one at MLT $=15$ and $\mathrm{MLAT}=81^{\circ}$ and the other one at MLT $=19$ and MLAT $=83^{\circ}$. The first minimum corresponds to the foci of the regular convection cell existing before the arc onset. The second minimum is "attached" to the arc and shifted toward the magnetic pole, in the direction of the arc's motion. So, the arc seems to form an additional cell existing on top of the background flow. With the weakening of the arc, the additional foci disappeared and only the regular convection cell was observed. Figure $11 \mathrm{~b}$ shows the convection pattern for the second arc when it was detached from the auroral oval. The measurements are more limited here. There is a large-scale dusk-side convection cell centered at MLAT $=77^{\circ}$ and MLT $=17$ that is highly perturbed near the arc location at MLAT $=80^{\circ}-85^{\circ}$ and MLT $=16-20$, with a significant latitudinal gradient of the potential/velocity.

Figure 11c shows a convection map and the PC arc location for the event of 20 December 2008, 02:08 UT. The PolarDARN velocity data corresponding to this convection map were given in Fig. 8. The arc is located close to the convection reversal within the global-scale duskside convection cell. There were insufficient data from other radars in the dusk sector so that it is impossible to say whether there is another cell located at lower latitudes as it was in the 9 December 2007 event.

Figure 11d gives convection map for the event of 7 November 2007, 09:56 UT. We demonstrated in Fig. 10 that the RKN radar shows Doppler velocity reversal away from the arc location. The mapping technique smoothed out this feature and shows it as a strong reduction in the flow dawnside of the arc. The arc itself is located within a region of anti-sunward flow and is not obviously related to two 

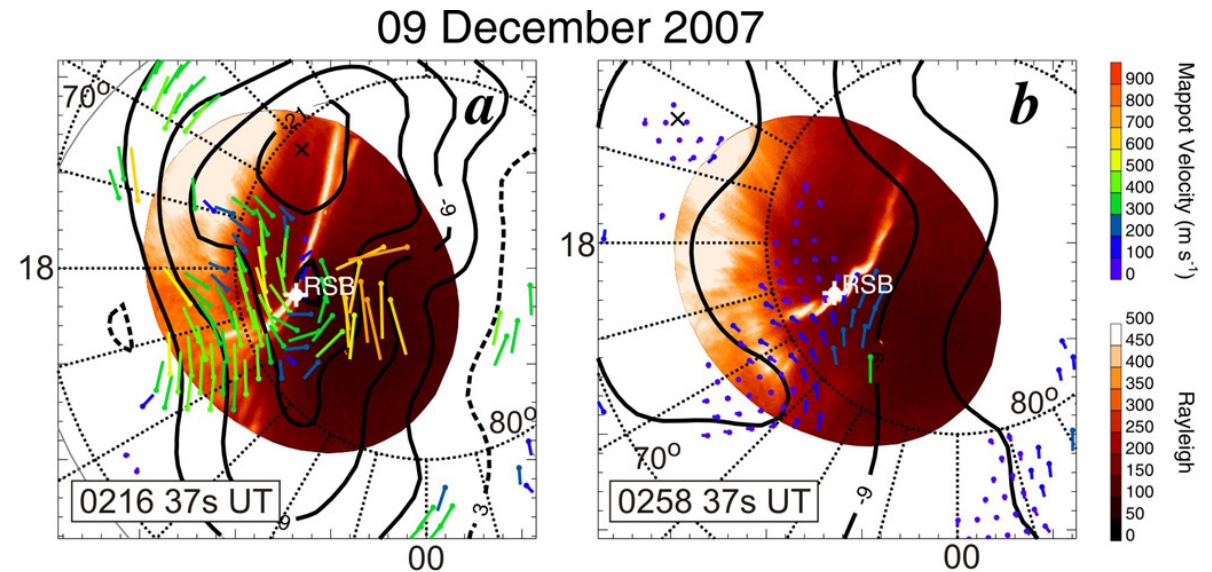

20 December 2008

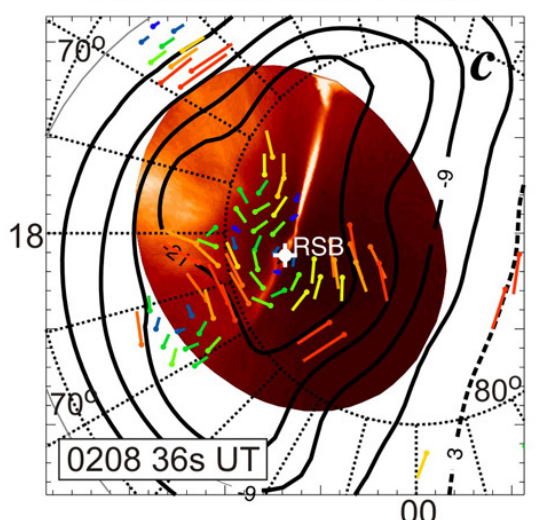

07 November 2007

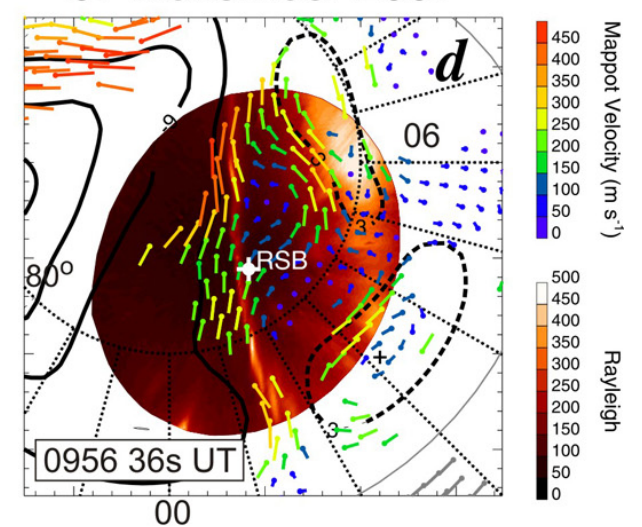

21 October 2007
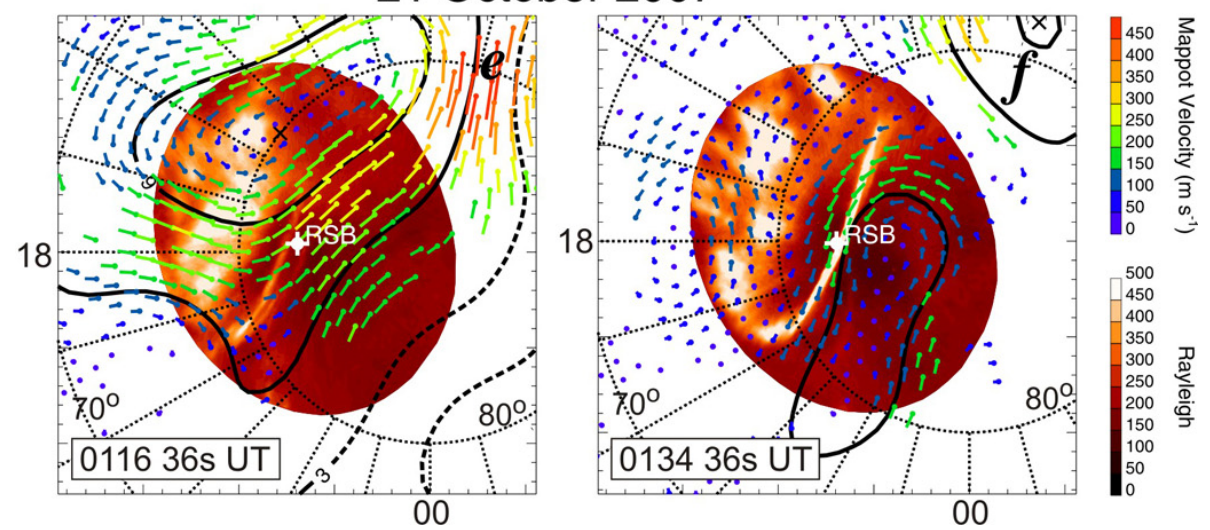

Fig. 11. SuperDARN convection maps with overlaid auroral images for selected scans on (a), (b) 9 December 2007, (c) 20 December 2010, (d) 7 November 2007 and (e), (f) 21 October 2007. Notice that for the 9 December 2007 event, panels (a) and (b), the scale on the velocity color bar is 2 times larger than for other events.

mesoscale convection cells seen in the dawn sector (these cells occur in regions of enhanced auroral oval luminosity).

So far convection maps presented for the PC events give the impression that the arcs do not significantly modify the overall global convection pattern; their onset leads to medium sized additional inclusions on top of a global pattern. We identified several events when PC arcs were show- ing more drastic changes of the overall pattern. These events were of different type, namely the arcs were originating at an auroral bright spot on the poleward edge of the nightside auroral oval and then protruding inside the polar cap, similar to those described by Berg et al. (1994). Figure 11e, f give one example of such an event, 21 October 2007. In this case, the arc emerged from a bright spot at $\sim 20$ MLT and 
MLAT $=80^{\circ}$ and then progressed poleward. The RKN 1-o$\mathrm{s}$ velocities were toward noon on the dusk side of the arc and away from noon on its dawnside. The FIT technique shows clearly that, while the arc was weak (Fig. 11e), the global convection pattern was probably controlled by processes associated with the bright auroral spots at 16-18 MLT and MLAT $\sim 80^{\circ}$, but as the arc intensified and started crossing the polar cap (Fig. 11f) it brought with itself a noonward flow that changed the overall pattern. The arc-associated flows being added to the background flow led to the occurrence of a new convection cell located dawnward of the arc.

\section{Discussion}

In this study, the Inuvik and Rankin Inlet PolarDARN HF radar measurements were combined with all-sky camera observations at Resolute Bay to investigate radar signatures of, and the plasma flows around, the polar cap arcs. For one case, 9 December 2007, selected for more detailed presentation, two separate arcs were considered both detaching from the poleward edge of the auroral oval at $\sim 15$ MLT and moving toward the dawn/magnetic pole across the polar cap and being stretched toward the Sun. In this sense, theses arcs could have been classified as Sun-aligned arcs. We identified signatures of the arcs in the echo power, Doppler velocity and spectral width and investigated modifications of the convection patterns associated with these arcs. We also presented radar data for several other PC arcs to illustrate additional radar signatures.

In terms of general morphology, the 9 December 2007 arcs were of typical duskside features reported for the RSB measurements in the past (Shiokawa et al., 1995; Hosokawa et al., 2011). The arcs were fairly bright and the motion was relatively steady. The speed of poleward progression was $\sim 300 \mathrm{~m} \mathrm{~s}^{-1}$. The equatorward "end" of the arcs was seen to be "buried' into the auroral oval luminosity band, similar to what has been reported for the theta aurora (Zhu et al., 1997; Frey, 2007; Newell et al., 2009). There were some dynamical changes in the arcs' configuration and in the plasma flows at the "juncture" of the arcs and the oval that were, however, not focused on in this study as our goal was to show signatures of the arcs in their central parts where the features are easier to identify.

The onset of the polar cap arcs is often related to variations in the IMF $B_{\mathrm{z}}$ and $B_{\mathrm{y}}$ (e.g. Hosokawa et al., 2011). We were unable to find an obvious trigger of the arcs in variations of the IMF $B_{\mathrm{y}}$ and $B_{\mathrm{z}}$ as well as in the solar wind dynamic pressure. One fact is certain: both arcs occurred some minutes after the IMF $B_{\mathrm{Z}}$ changed its polarity from positive to negative values. In this sense, the arcs were unusual since for most of the PC events identified the IMF $B_{\mathrm{Z}}$ was positive although some transient decreases to near zero or even negative values were seen, from time to time. An event similar to those reported in this study was recently discussed by Kozlovsky et al. (2009) with incoherent scatter radar data. Overall, considering other events, our data support the notion that PC arcs are predominantly a $B_{\mathrm{Z}}$ positive phenomenon (Rodriguez et al., 1997; Newell et al., 2009; Hosokawa et al., 2011).

In terms of the IMF $B_{\mathrm{y}}$, it was difficult to confidently identify a relationship with it for many events considered. For the 9 December 2007 events, the arcs were moving in the direction of the IMF $B_{\mathrm{y}}$ component, but for other events, this component was typically changing. The start of motion was sometimes consistent with the direction of IMF $B_{\mathrm{y}}$ (Kullen et al., 2002; Valladares et al., 1994) and was inconsistent with it in other events. This is similar to the report by Hosokawa et al. (2011) for the entire RSB data base.

In terms of the relationship to the auroral oval, two types of events have been identified. Arcs of one group were formed by splitting/detaching from the oval. This study focused on this type of PC arcs. It is very likely that processes of merging between the IMF and Earth's magnetic field were involved in their formation (e.g. Blomberg et al., 2005). Sojka et al. (1994) proposed the coupled magnetosphereionosphere model that considers a shear Alfvén wave interacting with the ionosphere. One of their predictions is that for background convection velocities of $>300 \mathrm{~m} \mathrm{~s}^{-1}$, the wave would lead to a splitting of the initial conductance band into fine structures and multiple arcs should be observed. This scenario seems to be consistent with observations of PC arcs in the 9 December 2007 event, both in terms of the sequential appearance of the arcs (there was a third very weak arc in that event that has not been discussed as the radars did not observe sufficient echoes) and over-threshold magnitude of the plasma drift. It is important that the velocity of the $\boldsymbol{E} \times \boldsymbol{B}$ drift measured by optical, radar, and CADI instruments were close to each other implying the arcs were drifting with the bulk of the plasma.

The second group of arcs were seen as protruding into the polar cap after intensification at the poleward edge of the midnight auroral oval (e.g. Fig. 11, 27 October 2007 event). These arcs were very likely formed through the evolution of interchange instabilities (e.g. Golovchanskaya et al., 2006). We did not present much information on this type of arcs except showing that they significantly modify the convection patterns and thus can be identified in the routine SuperDARN convection patterns, contrary to the arcs of the first group.

Radar signatures of the PC arcs in short-range, E-region echoes that we reported in this study are very similar to those reported by Koustov et al. (2008). We again noticed an echo power decrease in an area of strong luminosity and changes in the polarity (velocity reversal) of the plasma velocity component along the arc. The HF radar signatures of the PC arcs in the F-region backscatter showed some differences. The similarity was the decrease in echo power at the arc location for some events, as shown in Fig. 4d. In these cases, a strong bending of radio waves likely prevented F-region echo detection. Beyond this, for the five arc cases presented in this study, the power was enhanced in the wake of the moving 
arc. For some periods, echoes were detected on the leading edge of the arc as well, but these were usually much weaker (as in case of 7 November 2007 event, Fig. 10) and these echoes could well be background ones; these echoes would have been detected no matter whether the arc reached a specific gate of radar measurements.

Enhanced echo power in the arc's wake is highly expected for two reasons. First, this side of the arc is exactly where the conditions for the GD plasma instability are preferential as the background plasma gradient is directed toward the arc and the $\boldsymbol{E} \times \boldsymbol{B}$ plasma drift (shift of the arc) is in the direction of the plasma gradient. Secondly, the propagation conditions are better and average electron density is stronger on this side of the arc. In front of the arc, propagation conditions are usually not as good because of low density (no precipitation). The density is increased in the arc wake (e.g. Kozlovsky et al., 2007), which increases echo power. As the arcs were moving away from the ranges of optimal echo detection, the arc-associated echoes became less and less "visible" with eventually no echo returns at all (e.g. Fig. 3). The importance of the propagation condition is strongly supported by our data of Fig. 4 where no overlap between the RKN and INV echoes was seen; the radars detected echoes in their respective areas of optimal echo reception. In this respect we should note that winter time (when optical observations are performed at RSB), the PolarDARN radars seldom see Fregion echoes over RSB during early morning hours. For example, in December 2010 between 09:00 and 10:00 UT only 185 ionospheric echoes were detected in the RKN radar gates $25-27$, beam 5 while near magnetic noon hours, between 18:00 and 19:00 UT, the number of echoes was 893, which is a factor of 4 larger.

We note that the occurrence of HF echoes in the wake of moving PC arcs is in contrast to echo detection in front of the equatorward moving auroral zone arcs (Uspensky et al., 2001; Séran et al., 2009). For a case of evening auroral zone arcs, the electric field is enhanced just equatorward of the arc (Uspensky et al., 1983; Timofeev et al., 1987; Aikio et al., 2002). In addition, both the ionospheric latitudinal gradient of the electron density and slope in the electron density contours help in achieving the orthogonality condition in regions equatorward of an arc (Uspensky et al., 1993). In the case of polar cap observations, nighttime electron densities are usually low and the orthogonality condition is not easy to achieve.

The velocity of F-region echoes in this study also showed some differences with the E-region case discussed by Koustov et al. (2008). Whenever the RKN radar beams were oriented roughly along the arcs' extent, clear velocity reversals were observed with flows in the antisunward (toward the radar) direction on the dawnside of the arc and sunward (away from the radar) on the duskside, Figs. 4e, 9c. These observations are in agreement with Koustov et al. (2008); they indicate converging electric fields around the arcs as was seen in the auroral zone and in the polar cap (e.g. Doolittle et al., 1990; Gallaher, 1997; Kozlovsky et al., 2007). However, cases were presented where the flow reversals were not well seen, and in these cases the PC arc signatures in other parameters, such as the power and spectral width map, were better seen (Figs. 8f, 10c).

With the PolarDARN radars, it is hardly possible to establish the direction of the plasma flow within a PC arc even in favourable cases of the arc being aligned with some radar beams. The radar nominal range resolution is $45 \mathrm{~km}$. For radar ranges of $\sim 1500 \mathrm{~km}$ (distance to RSB), the radar beamwidth in the horizontal plane is about $\sim 120 \mathrm{~km}$. Thus the resolution of the radars is insufficient to detect the thin optical forms because the backscatter is being collected from both the inside and outside parts of the arcs. It is symptomatic that the velocity at the arc locations often shows strong variability, e.g. Fig. 9c.

The main arc signatures in the echo spectral width were similar to the case of Koustov et al. (2008); the width was enhanced in the vicinity of the arc (Figs. 4f, 10d). Several explanations of this result can be offered. One of these is the fact that each echo in the arc vicinity might be a collection of microscattering from various parts of the arc, both in terms of height and azimuth. Somewhat different areas might have slightly different velocities and their integration in one gate signal might lead to an unusually broad spectrum. The other explanation is strong natural non-homogeneity of the flows near the arc (Gallaher, 1997; Kozlovsky et al., 2007).

Previous publications did not show a clear picture of plasma flows around PC arcs (Newell et al., 2009). Carlson et al. (1988) and Mende et al. (1988) reported a great deal of structuring in the flows. Our observations are consistent with this result. Despite the fact that the arcs were seemingly homogeneous (over a certain distance), the velocity was changing a lot from one patch of data to another and the velocity trends were often difficult to infer. Consider Fig. 10c. For central beams in range gates 29-30 (these gates are enhanced by white color in Fig. 10c) velocities are anywhere between $-100 \mathrm{~m} \mathrm{~s}^{-1}$ and $+100 \mathrm{~m} \mathrm{~s}^{-1}$. If one scans azimuthally, at the same range, but in different beams, Fig. 10c shows the velocity changes up to $\pm 200 \mathrm{~m} \mathrm{~s}^{-1}$. One may argue that this is a typical variability of the velocity but one would expect more stability for the case of a regular optical form moving at roughly constant speed in the ionosphere.

\section{Conclusions}

The results of this study can be summarized as follows.

1. Several cases of PC arc observations with the RKN and INV PolarDARN radars were identified and analyzed. In two cases, discussed in greater details, the arcs detached from the poleward edge of the duskside auroral oval and progressed toward the magnetic pole/dawnward with a speed of $\sim 200-400 \mathrm{~m} \mathrm{~s}^{-1}$. The 
radar signatures of the arcs were identified as (a) enhanced echo power and (b) enhanced spectral width of F-region echoes in their wake. Similar features were seen in other events.

2. The arcs detaching from the auroral oval and their HF radar counterparts moved toward magnetic pole with speeds close to the $\boldsymbol{E} \times \boldsymbol{B}$ drift of the ionospheric plasma as inferred from optical, CADI ionosonde and radar Doppler data.

3. The plasma flows on opposite sides of some arcs were of different polarity (flow reversal). On the duskside (dawnside) the flow was sunward (antisunward). Thus the electric field distribution around the arcs was of a converging type. The background flows away from the arc locations were predominantly antisunward. On global convection maps some arcs did not show significant perturbations of the flow pattern while others occurred near the flow reversal line of additional mesoscale convection cells established poleward of regular convection cells characterizing the auroral oval flow.

4. Events were identified for which the arcs emerged from the poleward edge of the nightside auroral oval and protruded into the polar cap toward noon. Such arcs set mesoscale flow channels with the plasma moving toward noon (Sun) so that the global convection pattern was modified drastically.

Acknowledgements. This work was supported by Grants-in Aid for Scientific Research (16403007; 19403010; 20244080) from the Ministry of Education, Culture, Sports, Science and Technology of Japan, and by Project 2 of the Geospace Research Center, Solar Terrestrial Environment Laboratory. Resolute Bay CADI data collected within the CHAIN project (Canada) are acknowledged. The PolarDARN HF radars are operated by the U of Saskatchewan radar group with funding from the Canadian Space Agency and NSERC. AVK acknowledges the Solar-Terrestrial Environment Laboratory of Nagoya University for funding during his stay in Japan. The work was also supported by NSERC grant to AVK. Critical comments of the reviewers are greatly appreciated.

Topical Editor K. Kauristie thanks two anonymous referees for their help in evaluating this paper.

\section{References}

Aikio, A. T., Lakkala, T., Kozlovsky, A., and Williams, P. J. S.: Current systems of stable drifting auroral arcs in the evening sector, J. Geophys. Res., 107, 1424, doi:10.1029/2001JA009172, 2002.

Berg, G. A., Kelley, M. C., Mendillo, M., Doe, R., Vickrey, J., Kleitzing, C., Primdahl, F., and Baker, K. D.: Formation and eruption of Sun-aligned arcs at the polar cap oval boundary, J. Geophys. Res., 99, 17577-17589, 1994.

Blomberg, L. G., Cumnock, J. A., Alexeev, I. I., Belenkaya, E. S., Bobrovnikov, S. Yu., and Kalegaev, V. V.: Transpolar aurora: time evolution, associated convection patterns, and a possible cause, Ann. Geophys., 23, 1917-1930, doi:10.5194/angeo-231917-2005, 2005.

Carlson Jr., H. C., Heelis, R. A., Weber, E. J., and Sharber, J. R.: Coherent mesoscale convection patterns during northward interplanetary magnetic field, J. Geophys. Res., 93, 14501-14514, 1988.

Chisham, G., Lester, M., Milan, S. E., Freeman, M. P., Bristow, W. A., Grocott, A., McWilliams, K. A., Ruohoniemi, J. M., Yeoman, T. K., Dyson, P. L., Greenwald, R. A., Kikuchi, T., Pinnock, M., Rash, J. P. S., Sato, N., Sofko, G. J., Villain, J.-P., and Walker, A. D. M.: A decade of the super dual auroral radar network (SuperDARN): scientific achievements, new techniques and future directions, Surv. Geophys., 28, 33-109, doi:31210.1007/s10,712007-9017-8, 2007.

Doolittle, J. H., Mende, S. B., Robinson, R. M., Swenson, G. R., and Valladares, C. E.: An observation of ionospheric convection and auroral arc motion, J. Geophys. Res., 95, 19123-19129, 1990.

Eriksson, S., Provan, G., Rich, F. J., Lester, M., Milan, S. E., Massetti, S., Gosling, J. T., Dunlop, M. W., and Rème, H.: Electrodynamics of a split-transpolar aurora, J. Geophys. Res., 111, A11319, doi:10.1029/2006JA011976, 2006.

Frey, H. U.: Localized aurora beyond the auroral oval, Rev. Geophys., 45, RG1003, doi:10.1029/2005RG000174, 2007.

Gallagher Jr., H. A.: Radar and optical observations of plasma convection associated with very high-latitude auroral arcs, $\mathrm{PhD}$ Thesis, Boston College, USA, 1997.

Golovchanskaya, I. V., Kullen, A., Maltsev, Y. P., and Biernat, H.: Ballooning instability at the plasma sheet-lobe interface and its implications for polar arc formation, J. Geophys. Res., 111, A11216, doi:10.1029/2005JA011092, 2006.

Grant, I. F., MacDougall, J. W., Ruohoniemi, J. M., Bristow, W. A., Sofko, G. J., Koehler, J. A., Danskin, D., and André, D.: Comparison of plasma flow velocities determined by the ionosonde Doppler drift technique, SuperDARN radars, and patch motion, Radio Sci., 30, 1537-1549, doi:10.1029/95RS00831, 1995.

Greenwald, R. A.: Recent advances in the use of auroral backscatter to measure ionospheric electric fields, in: Dynamical and Chemical Coupling, edited by: Grandal, B. and Holtet, J. A., D. Reidel, Hingham, Mass., 1977.

Hosokawa, K., Shiokawa, K., Otsuka, Y., Nakajima, A., Ogawa, T., and Kelly, J. D.: Estimating drift velocity of polar cap patches with all-sky airglow imager at Resolute Bay, Canada, Geophys. Res. Lett., 33, L15111, doi:10.1029/2006GL026916, 2006.

Hosokawa, K., Moen, J. I., Shiokawa, K., and Otsuka, Y.: Motion of polar cap arcs, J. Geophys. Res., 116, A01305, doi:10.1029/2010JA015906, 2011.

Koustov, A., Hosokawa, K., Nishitani, N., Ogawa, T., and Shiokawa, K.: Rankin Inlet PolarDARN radar observations of duskward moving Sun-aligned optical forms, Ann. Geophys., 26, 2711-2723, doi:10.5194/angeo-26-2711-2008, 2008.

Kozlovsky, A., Aikio, A., Turunen, T., Nilsson, H., Sergienko, T., Safargaleev, V., and Kauristie, K.: Dynamics and electric currents of morningside Sun-aligned auroral arcs, J. Geophys. Res., 112, A06306, doi:10.1029/2006JA012244, 2007.

Kozlovsky, A., Turunen, T., and Massetti, S.: Field-aligned currents of postnoon auroral arcs, J. Geophys. Res., 114, A03301, doi:10.1029/2008JA013666, 2009. 
Kullen, A., Brittnacher, M., Cumnock, J. A., and Blomberg, L. G.: Solar wind dependence of the occurrence and motion of polar auroral arcs: A statistical study, J. Geophys. Res., 107, 1362, doi:10.1029/2002JA009245, 2002.

Liu, H.: Study of the high-latitude ionosphere with the Rankin Inlet PolarDARN radar, MSc Thesis, U of Saskatchewan, Saskatoon, Canada, 2010.

Mende, S. B., Doolittle, J. H., Robinson, R. M., and Vondrak, R. R.: Plasma drifts associated with a system of sun-aligned arcs in the polar cap, J. Geophys. Res., 93, 256-264, 1988.

Milan, S. E., Davies, J. A., and Lester, M.: Coherent HF radar backscatter characteristics associated with auroral forms identified by incoherent radar techniques: A comparison of CUTLASS and EISCAT observations, J. Geophys. Res., 104, 22591-22604, 1999.

Newell, P. T., Liou, K., and Wilson, G. R.: Polar cap particle precipitation and aurora: Review and commentary, J. Atmos. SolarTerr. Phys., 71, 199-215, 2009.

Ponomarenko, P. V. and Waters, C. L.: Spectral width of SuperDARN echoes: measurement, use and physical interpretation, Ann. Geophys., 24, 115-128, doi:10.5194/angeo-24-115-2006, 2006.

Rodriguez, J. V., Valladares, C. E., Fukui, K., and Gallagher, H. A.: Antisunward decay of polar cap arcs, J. Geophys. Res., 102, 27227-27247, doi:10.1029/97JA01727, 1997.

Ruohoniemi, J. M. and Baker, K. B.: Large-scale imaging of highlatitude convection with Super Dual Auroral Radar Network HF radar observations, J. Geophys. Res., 103, 20797-20811, 1998.

Safargaleev, V., Lyatsky, W., Gazey, N. G., Smith, P. N., and Kriviliov, V.: The response of the azimuthal component of the ionospheric electric field to auroral arc brightening, Ann. Geophys., 18, 65-73, doi:10.1007/s00585-000-0065-3, 2000.

Séran, E., Godefroy, M., Kauristie, K., Cerisier, J.-C., Berthelier, J.-J., Lester, M., and Sarri, L.-E.: What can we learn from HF signal scattered from a discrete arc?, Ann. Geophys., 27, 18871896, doi:10.5194/angeo-27-1887-2009, 2009.
Shiokawa, K., Yumoto, K., Hayashi, K., Oguti, T., and McEwen, D. J.: A statistical study of the motions of auroral arcs in the highlatitude morning sector, J. Geophys. Res., 100, 21979-21985, 1995.

Shiokawa, K., Otsuka, Y., and Ogawa, T.: Propagation characteristics of nighttime mesospheric and thermospheric waves observed by optical mesosphere thermosphere imagers at middle and low latitudes, Earth Planets Space, 61, 479-491, 2009.

Sojka, J. J., Zhu, L., Crain, D. J., and Schunk, R. W.: Effect of high latitude ionospheric convection on Sun-aligned polar cap arcs, J. Geophys. Res., 99, 8851-8863, 1994.

Timofeev, E. E., Vallinkoski, M. K., Kozelova, T. V., Yahnin, A. G., and Pellinen, R. J.: Systematics of arc-associated electric fields and currents as inferred from radar backscatter measurements, J. Geophysics, 61, 122-137, 1987.

Tsunoda, R. T.: High latitude irregularities: A review and synthesis, Rev. Geophys., 26, 719-760, 1988.

Uspensky, M. V., Kustov, A. V., and Williams, P. J. S.: The amplitude of auroral backscatter: III. Effect of tilted ionospheric layer, J. Atmos.Terr. Phys., 55, 1383-1392, 1993.

Uspensky, M., Eglitis, P., Opgenoorth, H., Starkov, G., Pulkkinen, T., and Pellinen, R.: On auroral dynamics observed by HF radar: 1. Equatorward edge of the afternoon-evening diffuse luminosity belt, Ann. Geophys., 18, 1560-1575, doi:10.1007/s00585-0011560-x, 2000.

Valladares, C. E., Carlson Jr., H. C., and Fukui, K.: Interplanetary magnetic field dependency of stable Sun-aligned polar cap arc, J. Geophys. Res., 99, 6247-6272, 1994.

Villain, J.-P., André, R., Pinnock, M., Greenwald, R. A., and Hanuise, C.: A Statistical study of the Doppler spectral width of high-latitude ionospheric F-region echoes recorded with SuperDARN coherent HF radars, Ann. Geophys., 20, 1769-1781, doi:10.5194/angeo-20-1769-2002, 2002.

Zhu, L., Schunk, R. W., and Sojka, J. J.: Polar cap arcs: a review, J. Atmos. Terr. Phys., 59, 1087-1126, 1997. 